\title{
Impact of Noninvasive Follicular Thyroid Neoplasm with Papillary-Like Nuclear Features (NIFTP) on the Outcomes of Lobectomy
}

\author{
Pedro Weslley Rosario, MD \\ Instituto de Ensino e Pesquisa da Santa Casa de Belo Horizonte, Belo Horizonte, MG, Brazil
}

\section{TO THE EDITORS:}

I have read with great interest the recent systematic review by Gartland and Lubitz. Their results and conclusion suggest that lobectomy and total thyroidectomy yield comparable oncologic outcomes for papillary thyroid carcinoma (PTC) measuring 1-4 cm. ${ }^{1}$ Although the authors themselves recognize this limitation, I highlight the confounding role that noninvasive follicular thyroid neoplasm with papillary-like nuclear features (NIFTP) can play in the results.

As already known, the noninvasive encapsulated follicular variant of papillary thyroid carcinoma (EFVPTC) is no longer considered "cancer", and these tumors currently are termed NIFTP. Tumors that currently correspond to NIFTP were previously classified in the low-risk PTC group. If the virtual absence of recurrences after complete resection of NIFTP are considered, the rate of tumor persistence/recurrence in low-risk PTC recalculated after the exclusion of NIFTP somehow increases. Obviously, the magnitude of this increase depends on the frequency of NIFTP in the population studied.

In general, 15\% of our patients with PTC larger than $1 \mathrm{~cm}$ received the diagnosis of NIFTP after revision. ${ }^{2}$ However, if only the cases of low-risk PTC larger than $1 \mathrm{~cm}$ seen in recent years $(n=356)$ are considered, NIFTP would be diagnosed in $27.4 \%$ of the cases. In another study, NIFTP corresponded to $37.5 \%$ of low-risk PTC. ${ }^{3}$

Even before noninvasive EFVPTC was no longer considered cancer, patients with exclusive indeterminate cytology were already more frequently submitted to

(C) Society of Surgical Oncology 2018

First Received: 25 September 2018;

Published Online: 29 October 2018

P. W. Rosario, MD

e-mail: pedrowsrosario@gmail.com lobectomy, and this cytologic result is known to be more frequent in EFVPTC than in classical/aggressive PTC. Therefore, the frequency of NIFTP likely is even higher among patients with low-risk PTC larger than $1 \mathrm{~cm}$ submitted to lobectomy. The data of Rajjoub et al. ${ }^{4}$ corroborate this impression. Among patients with PTC 1- to 4-cm/N0-Nx/ M0, 55\% of those undergoing lobectomy had FVPTC compared with $35 \%$ of those submitted to total thyroidectomy). ${ }^{4}$

If NIFTP indeed accounts for one-third to one half of low-risk PTC measuring 1-4 cm and submitted to lobectomy, recalculation of the recurrence and mortality rates after exclusion of these tumors can significantly increase the aforementioned rates (even double them). Consequently, the conclusion that lobectomy is sufficient for low-risk PTC measuring $1-4 \mathrm{~cm}$ might be questioned. Even in the case of FVPTC, after the exclusion of NIFTP and recalculation of the rates considering only the invasive and infiltrative encapsulated variants, the conclusion possibly is different.

\section{COMPLIANCE WITH ETHICAL STANDARDS}

ETHICAL APPROVAL The study was approved by the Research Ethics Committee of our institution.

DISCLOSURE There is no conflict of interest.

\section{REFERENCES}

1. Gartland RM, Lubitz CC. Impact of extent of surgery on tumor recurrence and survival for papillary thyroid cancer patients. Ann Surg Oncol. 2018;25:2520-5.

2. Rosario PW, Mourão GF, Nunes MB, Nunes MS, Calsolari MR. Noninvasive follicular thyroid neoplasm with papillary-like nuclear features. Endocr Relat Cancer. 2016;23:893-7.

3. Wong KS, Strickland KC, Angell TE, Nehs MA, Alexander EK, Cibas ES, et al. The flip side of NIFTP: an increase in rates of unfavorable histologic parameters in the remainder of papillary thyroid carcinomas. Endocr Pathol. 2017;28:171-6.

4. Rajjoub SR, Yan H, Calcatera NA, Kuchta K, Wang CE, Lutfi W, et al. Thyroid lobectomy is not sufficient for T2 papillary thyroid cancers. Surgery. 2018;163:1134-43. 